América sin Nombre, n.o 21 (2016): 129-139

DOI: 10.14198/AMESN.2016.21.10

ISSN: 1577.3442 / eISSN: 1989-9831

Fecha de recepción: 26/04/2016

Fecha de aceptación: 12/10/2016
Puede citar este artículo como:

Rodilla León, María José. «Algunos comentarios a las ediciones de los Coloquios espirituales y sacramentales de Fernán González de Eslava». Teatro breve virreinal. Miguel Zugasti (coordinador). América sin Nombre, 21 (2016): 129-139, DOI: 10.14198/AMESN.2016.21.10

Link para este artículo: http://dx.doi.org/10.14198/AMESN.2016.21.10

\title{
Algunos comentarios a las ediciones de los Coloquios espirituales y sacramentales de Fernán González de Eslava
}

\author{
Some Commentaries on the various Editions of the Coloquios espirituales $y$ \\ sacramentales by Fernán González de Eslava
}

\author{
María José Rodilla LeÓN* \\ UAM-Iztapalapa
}

\begin{abstract}
Resumen
El propósito de este ensayo es enriquecer las anotaciones de las ediciones de Coloquios espirituales y sacramentales de uno de los más importantes dramaturgos de la Nueva España, Fernán González de Eslava, situando la obra en su contexto histórico para reconstruir la historia y las costumbres de la época virreinal: las guerras, epidemias, prejuicios, prohibiciones, la Ciudad y sus fiestas, etc. Algunos de los aspectos comentados son: los obrajes, los caballos y carrozas en la Ciudad, las alcabalas, la guerra contra los Chichimecas, los naipes y la prohibición de la seda.
\end{abstract}

Palabras clave: Coloquios, González de Eslava, ediciones, anotaciones, costumbres virreinales

\section{Abstract}

The purpose of this essay is to enrich the annotations to the various editions of the Coloquios espirituales y sacramentales, a work by one of the most important playwrights of New Spain, Fernán González de Eslava. This will be accomplished by placing the work within its historical context, so as to reconstruct the history and conventions of the viceregal period: the wars, epidemics, prejudices, tax systems, prohibitions, the city and its celebrations, etc. Some of the aforementioned aspects to be mentioned in this essay are the following: textile plants, horses and carriages in the city, sales tax, the war against the Chichimecas, card playing, and silk prohibition.

Keywords: Coloquios, González de Eslava, editions, annotations, viceregal conventions.

\footnotetext{
* Licenciada en Filología Románica (Universidad de Extremadura, España) y Doctora en Letras Hispánicas (El Colegio de México). Profesora-Investigadora de literatura medieval, Siglos de Oro y los Virreinatos, en la Universidad Autónoma Metropolitana-Iztapalapa, México. Ha participado en congresos de literatura medieval, áurea y virreinal y ha publicado diversos ensayos sobre Bestiarios, viajeros, de caballerías, sobre Cervantes y de cultura virreinal. Miembro del Sistema Nacional de Investigadores y autora de las siguientes obras: - Lo maravilloso medieval en "El Bernardo» de Balbuena, México, UNAM-UAM-I, 1999.

- Edición crítica de Claribalte, de Gonzalo Fernández de Oviedo, México, UNAM-UAM-I, 2002.

- Edición anotada de Infortunios de Alonso Ramírez, de Carlos de Sigüenza y Góngora, México, Alfaguara-Santillana, 2003.

- Escrito en los virreinatos, México, UNAM, Seminario de Cultura Literaria Novohispana, 2004.

- Edición anotada de El peregrino indiano, de Antonio de Saavedra Guzmán, Madrid-Frankfurt, Iberoamericana-Vervuert, 2008.

- "Aquestas son de México las señas». La capital de la Nueva España según los cronistas, poetas y viajeros (siglos XVI al XVIII), Madrid, Iberoamericana - Vervuert - UAM, 2014.
} 
Uno de los grandes dramaturgos virreinales del siglo XVI es Fernán González de Eslava, en cuya obra Coloquios espirituales y sacramentales aparecen algunos sucesos cotidianos de la Nueva Espańa revestidos de un ropaje religioso: dos entradas de virreyes, una consagración de un obispo, la construcción de un obraje, etc., que nos permiten reconstruir la historia y las costumbres de la época virreinal, las prohibiciones, los prejuicios, las epidemias, las guerras contra los chichimecas. A esa recreación de época dedicaré las páginas que siguen con el propósito de enriquecer las anotaciones de las ediciones de su obra dramática: la de García Icazbalceta (1877), la de Rojas Garcidueñas (1958), que sigue las notas de Icazbalceta y añade algunas más, y la de Othón Arróniz, completada por Sergio López Mena (1998), que suele citar a Icazbalceta; sin duda, la edición más valiosa porque, además de detectar algunas fuentes de dramaturgos españoles, fechó entre 1565 y 1590 cada uno de los coloquios y para ello hubo de analizar muchas de las referencias históricas. Qué duda cabe que un moderno editor se nutrirá siempre de las ediciones anteriores, valiosas en su tiempo, y mucha de su información aún válida hoy, pero otras notas adolecen de comentarios que pueden completarse situando la obra en el contexto histórico y éste es mi propósito. Siguiendo la datación histórica de Arróniz ${ }^{1}$, se verán algunas de las referencias novohispanas que aparecen en siete (I, III, V, VI, VII, XV y XVI) de los dieciséis Coloquios que escribiera el sacerdote González de Eslava y publicara en 1610 su amigo, el fraile agustino Fernando Vello de Bustamante.

Coloquio I - El Obraje divino (1574-1580). En este primer Coloquio encontramos la primera referencia, ya que la loa está a cargo del personaje de Nueva España, quien le explica al virrey el argumento de la obra y le ofrece un corazón que representa a todos los de dicha región. En el argumento recitado, Nueva España dice:

Trátase con sancto zelo de los Obrajes que tiene nuestro Dios en tierra y cielo. (I, vv. 33-35)

1. Fernán González de Eslava, Coloquios espirituales y sacramentales, ed. Othón Arróniz y Sergio López Mena. México: UNAM, 1998. En adelante, citaré por esta edición, señalando el número de coloquio en números romanos, y después los versos correspondientes en numeración arábiga.
A la prosperidad y aclimatación de estas fábricas textiles se refiere el contador Alonso de Zorita cuando nos informa que entre los productos que se expor$\tan$ o «que se sacan» de la ciudad para otras partes, destacan los paños finos, cobertores, mantas y frazadas de los obrajes para Guatemala, Nicaragua, Perú y Honduras; seda, terciopelos, tafetanes, rasos y damascos de todos los colores para Perú; habla sobre el añil que servía para teñir las telas y que se llevó en grandes cantidades en la flota de la Nueva España en 1578 (234-236). González de Eslava sabe aprovechar esta opulencia textil para trasladarla al plano teológico y dedicar este coloquio al obraje divino. Igualmente, a manera de anotaciones de similia, pueden servirnos los tercetos de Grandeza mexicana de Bernardo de Balbuena, y, en concreto, el capítulo IV, donde se destaca la variedad de oficios y la importancia de la industria de los obrajes, citados en dos ocasiones:

Telares de oro, telas de obra prima, de varias sedas, de colores varias, de gran primor, gran gala y grande estima. (IV, 4)

De finas telas y de urdimbres bajas, obrajes ricos donde a toda cuenta se labran paños y se prensan rajas. (IV, 20)

Era tanta la riqueza y abundancia de obrajes que hubo de reformarse y tasarse este estanco. En 1589, el virrey dio dos autos a los letrados en los que se pregonaba que serían quitados los obrajes, pero se comisionó a Jerónimo López y a Alonso Domínguez para que hablaran "con el virrey a fin de obtener su consentimiento para seguir las diligencias necesarias para que esto no se lleve a cabo, pues perjudicaría considerablemente a la Ciudad» (AHCM, acta 5049, 28 de julio de 1589). Los pros y los contras sobre estas fábricas se suceden y las preocupaciones de las autoridades y los asesores continúan, como queda asentado en un documento que los padres Antonio Rubio y Pedro de Hortigosa remiten al virrey Luis de Velasco, en 1594: «En esta Nueva España hay mucha cantidad de obrajes, de todos géneros, en mayor número de los que serán menester para el abasto y proveimiento de la república [...] si no se pone tasa en los precios es un monopolio dañoso» (Cuevas, "Puntos», 482-484). Creo apuntalar con estos breves comentarios un tema al que no dieron demasiada importancia sus editores; Icazbalceta, por ejemplo, apenas anota que los obrajes «tomaron gran vuelo en el gobierno del primer virrey don Antonio 
de Mendoza y todavía en el siglo XVII constituían una industria floreciente» (293).

Más adelante, en este mismo coloquio, la didascalia anuncia que entra el Hombre desnudo en un caballo muy aderezado, que representa la sensualidad, y lleva el freno de la razón raído. Más de 150 versos dedica González de Eslava al tema del caballo que tanta importancia tuvo en la Nueva España, y, sin embargo, sus editores no reparan en él. Mencionado con asiduidad por autores de Relaciones de fiestas y por los viajeros, que llegaron a verlo como una auténtica marca de la sociedad novohispana, heredera de la española, lo encontramos frecuentemente en la historiografía de la época: cedularios, pragmáticas y actas de cabildo, porque el caballo formaba parte del ajuar del español de Indias, pertenecía a su código medieval trasladado a las nuevas tierras. En este coloquio I, se habla del caballo enjaezado con "galas agenas», de la casta del caballo y de la manera de montarlo y en los vv. 306-307, el Hombre dice: «Bien apuntas la gineta. / ¿Deprendiste de la brida?» Arróniz anota que la jineta era una lanza, lo cual no corresponde al contexto, pero además desconoce la expresión "montar a la jineta", que también aparece en el Quijote, en el episodio de la Dulcinea encantada, donde Sancho aprecia las habilidades de su ama que "puede enseñar a subir a la jineta al más diestro cordobés o mejicano» (Cervantes, Quijote, 650). Para una correcta anotación de estos versos, hay que acudir a los manuales de Albeytería de los siglos XVI y XVII, pródigos en esta literatura de equitación, mucha de ella escrita por indianos ${ }^{2}$ y al invaluable Tesoro de Covarrubias, que anota que en España se usaba «la jineta, un género de caballería africana, con frenos o bocados recogidos y estribos anchos y de cortas acciones», y a estos los llamaron jinetes y llamaron bridones a los que tenían los estribos largos y la pierna tendida, más propia de la caballería para hombres de armas. Bernal Díaz del Castillo nos ilustra sobre el valor de los jaeces, incluso para los indios, que los ofrecían a sus dioses como trofeos ganados a sus enemigos: "y hallaron en unos cúes de aquel pueblo muchos vestidos y armas y frenos de caballos

2. Pedro de Aguilar. Tratado de la cavallería a la gineta. Sevilla, 1572; Suárez de Peralta. Tractado de la Caballería de la Gineta y Brida. Sevilla, 1580; Gregorio de Tapia y Salcedo. Exercicios de la gineta. Madrid, 1643; Andrés Dávila y Heredia. Palestra particular de los exercicios del caballo. Valencia, 1674. Citados en García Santo-Tomás, 2004, p. 95. Véase también Chevalier, quien cita el Libro de alveytería de Juan Suárez de Peralta: Biblioteca Nacional de España, Ms. 4255. y dos sillas, y otras muchas cosas de la jineta, que habían presentado a sus ídolos» (415). Por los años en que está fechado este coloquio, estaba candente el tema del caballo como fuerza, protección y defensa de la tierra. En las Ordenanzas de la Mesta de Nueva España de 1574 se establecía que «ningún mestizo, indio, ni mulato, ni negro libre pueda tener ni tenga caballo propio suyo en manera alguna»; y la de 1680, que recogía dos reales disposiciones de Felipe II de 1568 y 1570 , prohibía «que los indios anden a caballo, y mandamos a los justicias que así lo hagan guardar y ejecutar sin remisión alguna» (Serrera 272). Un nuevo guińo de González de Eslava a un tema muy tratado en su época, que pasó inadvertido a sus editores, porque bien podía haber presentado al Hombre desnudo y necesitado del paño que sale del Obraje divino, pero no tendría por qué ir a caballo, utensilio difícil para la representación pues se requeriría hacer uno de cartón.

Coloquio III - A la consagración del Dotor Don Pedro Moya de Contreras, primer Inquisidor desta Nueua España, y Arçobispo desta santa Yglesia Mexicana. Trata del desposorio que entre ella y él contraxeron este dia (1574).

Con motivo de la llegada del arzobispo Pedro Moya de Contreras, en 1574, se representó El desposorio espiritual entre el Pastor Pedro y la Iglesia mexicana, de Juan Pérez Ramírez, "considerada como la primera producción teatral de ingenio criollo en toda América» (María y Campos 50), además de este coloquio tercero y el Entremés de las alcabalas, en un tablado junto al altar mayor de la catedral esa tarde de la consagración; pocos días después de la representación, Eslava fue encarcelado durante diecisiete días, porque el virrey Martín Enríquez se sintió aludido, ya que se acababa de introducir un nuevo impuesto en la Nueva España, a pesar de que el Entremés de las alcabalas ni siquiera era de nuestro dramaturgo, pero se representó en los entreactos de su coloquio (Villancicos, ed. M. Frenk 16), que sí era de su autoría. Varias actas de cabildo demuestran una gran preocupación respecto a la alcabala: «Se discutió una comunicación del virrey Martín Enríquez sobre la alcabala y la necesidad de organizarse para su funcionamiento" (AHCM, acta 3989, 31 de mayo de 1577). «Se acordó que Gerónimo López y Bernardino de Albornoz discutan con el virrey Martín Enríquez sobre el encabezamiento de la alcabala, y tomar una decisión antes de que parta la flota a España» (AHCM, acta 4165, 5 octubre de 1579). «Se acordó presentar al virrey [...] que 
los derechos de alcabala no dejan que haya ganancia en el comercio, y han hecho que el reino decaiga» (AHCM, acta 4270, 30 de marzo de 1581). Las quejas por el comercio de la tierra continuaron con los siguientes virreyes, Conde de la Coruña y Pedro Moya de Contreras.

Este coloquio III puede considerarse metafestivo porque en él se representa la fiesta misma: nos enteramos por boca del personaje Vanagloria que repican las campanas y hay grandes regocijos, «vozes y estruendo", así como mensajeros que publican la fiesta de las bodas. En los parlamentos de los pastores Recato y Cuidado, se hace la apología del prelado anterior, el dominico Alonso de Montúfar, y la tristeza por su muerte se convierte pronto en alegría con las nuevas de la boda entre el pastor Pedro y la pastora Iglesia. Las bodas son concertadas por el rey y el papa:

Que desde su eterna silla
les tocó y hizo notorio
este santo desposorio
al gran León de Castilla
y al Santo Papa Gregorio. (III, vv. 336-340)

Pureza anuncia que todo el pueblo espera ya a los esposos, se alude al menú que se servirá y el personaje de Nueva España quiere ofrecerle chapines a la desposada, pero se presenta con un corazón en la mano como en la loa del coloquio I, y los pajes, Rectitud y Pureza, acuden con platos de colación. Al esposo lo van invistiendo con su indumentaria, la mitra, el cayado y se va explicando su simbología, puesto que se trata de un teatro para enseńar al pueblo, instruirlo en los misterios de la fe y con el ánimo de moverlo a la devoción, al mismo tiempo que lo entretenía con las canciones intercaladas, o bien con los graciosos, que aparecen en la sexta Jornada: Adulación, quien jura por el volcán de Nicaragua y Vanagloria le cuestiona por qué no jura por el volcán de la Puebla, el Popocatépetl, y ella contesta que por temor a que se salgan los diablos que lo habitan y es que desde la Edad Media, los volcanes eran considerados como las puertas del infierno y así lo dice el personaje Guiñador al Príncipe en el coloquio XVI, que se sabe «vn atajo para ir al Infierno, que es la boca del Bolcán» (XVI, 637). Lo que, sin duda, haría reír al público eran las proezas que contaba Adulación de cómo le dio al diablo una coz en el estómago que lo dejó corcovado y una cuchillada «con la uña del dedo margarite» (222), aunque luego se condolió de la mujer del diablo, que venía "con tres o quatro diablillos de la mano, y creo que estarán ya grandes» (III, 222). Enseñanza, a través de la explicación simbólica y entretenimiento, en boca de los graciosos, eran el binomio perfecto para asimilar el coloquio, además de las referencias conocidas por el pueblo, como el volcán de la Puebla.

Coloquio V - De los siete fvertes que el virrey don Martín Enríquez mandó hazer con guarnición de soldados, en el camino que va de la ciudad de México a las minas de Zacatecas para euitar los daños que los chichimecos hazian a los mercaderes y caminantes que por aquel camino passauan (1570-1580). En la loa al virrey se explica el argumento de los «siete fuertes admirables» que se construyeron contra los asaltos del «Chichimeco embrauecido» y se simbolizan en los siete sacramentos. Las actas de cabildo abundan en este problema de seguridad en los caminos para los súbditos del virreinato hacia las minas de Guanajuato, Zacatecas y Guadalajara, sobre todo, en el gobierno del virrey Martín Enríquez: «Se acordó presentar al virrey [...] que los salteadores chichimecas han hecho gran daño y no se ha puesto remedio [...] los chichimecas impiden que se pueblen y trabajen minas muy ricas, han cometido muchas crueldades y destruido haciendas, y esto no se ha remediado (AHCM, acta 4270, 30 de marzo de 1581). Desde 1532 , se permite que se trate a los chichimecas como esclavos y en tiempos de Luis de Velasco, el primero, se pide «que el virrey y la Audiencia de México castiguen a los chichimecas y a los güauchichiles levantados aunque no estén dentro de sus jurisdicciones" (AHCM, acta 2655, 9 de enero de 1562). "Que se den facultades al virrey Luys de Velasco para castigar a los saltadeores chichimecas y huachichiles» (AHCM, acta 2683, 29 de abril de 1562). En la época en que está fechado este coloquio parece que se agudizan los problemas con los chichimecas y el virrey Martín Enríquez pretende que los afectados carguen con el costo de la guerra: «Leonel de Cervantes y Juan de Sámano informaron que se necesitan 25000 pesos de oro común para la pacificación de los chichimecas y guachichiles y que considera el virrey que se deben repartir entre los encomenderos, dueños de estancias, mineros, carreteros y mercaderes» (AHCM, acta 3452, 30 de agosto de 1570). Años después, se propone que se nombren 20 caballeros capitanes con el propio Martín Enríquez como general a la cabeza, con el propósito de aislarlos de los pueblos a los que atacaban y someterlos como esclavos (AHCM, acta 3909, 16 de abril de 1576). Todavía en los tiempos del arzobispo-virrey se sigue pidiendo que se ponga 
remedio a los daños que causan los chichimecas: "para que se declare a los indios chichimecas enemigos a sangre y fuego del rey y de la cristiandad, para así poder hacerles guerra, lo cual no ha sido posible por que hasta ese momento sólo eran considerados delincuentes. Y de no hacerse así se tendrán que seguir lamentando los muchos daños que ocasionan» (AHCM, acta 4644, 31 de mayo de 1585).

A pesar de la seriedad con la que está tratado el coloquio de los siete fuertes, González de Eslava desinfla este problema virreinal en el coloquio XVI, cuando el gracioso Coxín, una suerte de personaje folklórico como el Diablo Cojuelo, dice que ha «estado enfermo de comer un mal cozinado de las tripas de un indio chichimeco, que se me pegaron en el estómago y e estado para morirme» (XVI, 639).

Las Relaciones de fiestas, en el siglo siguiente, recuerdan a los chichimecas, en las procesiones, donde se recrea su barbarie en los bailes para conservar el recuerdo de un pasado guerrero y salvaje, como sucede en las Glorias de Querétaro (1680), de Sigüenza y Góngora.

Coloquio VI - Que se hizo para la fiesta del Santíssimo Sacramento en la ciudad de México, en la entrada del Conde de Coruña, quando vino por virrey desta Nueva España. Va simbolizando a la entrada que Dios haze en el alma (1580). Se dedica este coloquio, como reza el título, a la entrada en la ciudad del virrey Conde de Coruña, Lorenzo Suárez de Mendoza, y se simboliza en la entrada de Dios en el alma. Nuestro poeta y dramaturgo participa en esta recepción para darle la bienvenida al virrey con una loa que se declamaba bajo los arcos o con pequeńas representaciones, como la que se hace en esta loa, donde se realzan los blasones y las hazañas de los antepasados del virrey por boca de Marte. Otros personajes se presentan ante el Príncipe Soberano, porque, a su vez, es un coloquio para la fiesta del Santísimo Sacramento; entonces la ciudad, simbolizada en el Alma, salía a recibir a Cristo:

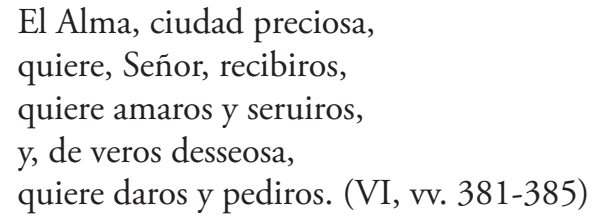

Y, al mismo tiempo, con "fiestas» y "galas», se recibía al príncipe que iba a gobernar la Nueva España. Desde la loa se anuncian las fiestas y el acatamiento de Marte al nuevo virrey, que se rinde a sus pies.
Fortaleza, Fe, Entendimiento y Concierto, a través de su diálogo, van describiendo la ciudad enfiestada, sus calles, sus regidores y el camino de los virreyes hasta la Ciudad con las paradas clave: Veracruz, Tlaxcala -que se prestan para la lectura teológica por la Cruz y porque Tlaxcala quiere decir, 'tierra de pan', como explica García Icazbalceta (76)-, Puebla, Otumba y la entrada en la Ciudad bajo palio, al igual que la hostia, que viene en el cáliz, cubierto con un velo. En el itinerario de los virreyes había pequeñas ceremonias desde que desembarcaban en Veracruz, pasando por Tlaxcala, a donde solían llegar los comisionados por la Real Universidad a recibirlos, o bien a Puebla, donde se preparaban grandes festejos que, a veces, querían competir con la capital. González de Eslava conoce perfectamente el itinerario de recepción de los virreyes desde su desembarco hasta la llegada a la Ciudad y lo recrea admirablemente en esta pieza.

En este mismo coloquio, González de Eslava creó a dos fulleros que, jugando a las presas, hacían gala de expresiones del juego de naipes y acababan a cuchilladas porque uno de ellos, Lope Bodigo, decía que ganaba sus dineros con los «naypes floreados» (v.475) o las cartas "robladas», que descubre Iuan Garauato, es decir, marcadas, señaladas, como anota Icazbalceta (77), para hacer fullerías:

\begin{tabular}{|c|c|}
\hline IUAN & ¡Ola! ¡Ce!, Lope Bodigo. \\
\hline Lope Bodigo & ¿Qué quieres, Iuan Garauato? \\
\hline IUAN & ¿Dónde vas? \\
\hline Lope Bodigo & $\begin{array}{l}\text { A ver un rato } \\
\text { jugar en cas de un amigo, } \\
\text { por ver si me dan barato. }\end{array}$ \\
\hline IUAN & $\begin{array}{l}\text { ¿Vas a hacer de tus gatas, } \\
\text { las que sueles en jugar? }\end{array}$ \\
\hline Lope Bodigo & $\begin{array}{l}\text { No me puedo passear, } \\
\text { que he hecho diez mil baratas } \\
\text { y me quieren executar. [...] }\end{array}$ \\
\hline IUAN & Vamos a ver esta fiesta. \\
\hline Lope Bodigo & Antes quiero que juguemos. \\
\hline IUAN & ¿Ay naipes? No los tenemos. \\
\hline Lope Bodigo & Mira qué baraja aquésta. \\
\hline IUAN & Pues aquí nos assentemos. \\
\hline Lope Bodigo & ¿Sobre qué quieres que corra? \\
\hline IUAN & $\begin{array}{l}\text { Hasta que me den la paga, } \\
\text { sobre la espada y la daga. }\end{array}$ \\
\hline Lope Bodigo & Yo pongo en prendas la gorra. \\
\hline IUAN & Dessa suerte, assí se haga. \\
\hline Lope Bodigo & $\begin{array}{l}\text { ¡O, qué bien que los meneas! } \\
\text { Mira que tengo este rey. }\end{array}$ \\
\hline IUAN & Hasme dado con la ley. \\
\hline
\end{tabular}




\begin{tabular}{|c|c|}
\hline Lope Bodigo & $\begin{array}{l}\text { Mejor, hermano, te veas } \\
\text { entre las patas de un buey. }\end{array}$ \\
\hline IUAN & $\begin{array}{l}\text { Dejémonos de trayciones, } \\
\text { que esta carta está roblada. }\end{array}$ \\
\hline LOPE BODIGO & ¿Al maestro, cuchillada? \\
\hline IUAN & $\begin{array}{l}\text { Tú me pones trascartones } \\
\text { y a mí no se me da nada. }\end{array}$ \\
\hline Lope Bodigo & $\begin{array}{l}\text { ¿Puede estar un hombre cuerdo } \\
\text { tratándole de tal arte? } \\
\text { Agora saco la parte. }\end{array}$ \\
\hline IUAN & $\begin{array}{l}\text { Anda, que si yo la pierdo, } \\
\text { correrá en el talabarte. }\end{array}$ \\
\hline Lope Bodigo & $\begin{array}{l}\text { ¡Miren qué suerte que tomo! } \\
\text { Plega a Dios que en estas manos } \\
\text { caygan cáncer y gusanos. }\end{array}$ \\
\hline IUAN & $\begin{array}{l}\text { Plega a Dios que sean de plomo } \\
\text { entretanto que jugamos. }\end{array}$ \\
\hline Lope Bodigo & ¡El buen dezir cómo engorda! \\
\hline IUAN & Presa y pinta de la guía. \\
\hline Lope Bodigo & $\begin{array}{l}\text { Ta, ta, que es vellaquería, } \\
\text { que passastes carta gorda } \\
\text { y allí va la suerte mía. }\end{array}$ \\
\hline IUAN & $\begin{array}{l}\text { Por cierto, que no he passado, } \\
\text { y si lo dizes tú, mientes. }\end{array}$ \\
\hline Lope Bodigo & ¡O, Dios!, ¿y aquesto consientes? \\
\hline IUAN & $\begin{array}{l}\text { Págame lo que he ganado } \\
\text { o te sacaré los dientes. (VI, vv. } \\
400-455 \text { ) }\end{array}$ \\
\hline
\end{tabular}

Respecto a este tipo de juegos, desde la segunda década del siglo Xvi, se prohibió jugar naipes o dados (AHCM, Acta 38, 1 de febrero de 1525); en 1539, el virrey don Antonio de Mendoza había prohibido que se jugara a los naipes, excepto «al tres dos y al triunfo, malillas, y ganapierde de cartas" (Cuevas, "Ordenanzas», 91) y en estos pocos que se permitían, no se podían jugar más de seis pesos de oro común al día, tampoco se debía jugar en sitios ocultos ni a puerta cerrada. Los más vigilados eran los mercaderes, porque se solía jugar en las tiendas, por lo que se les avisaba de la multa de diez pesos de oro. Cincuenta años después, se seguía jugando y continuaban las prohibiciones, sobre todo, para las mujeres, que parecían ser las más viciosas, a las que se les quitaba también toda ocasión de reunirse:

que las dichas mujeres, casadas ni solteras, doncellas ni viudas, jueguen en sus casas ningunos juegos de naipes, dados, tablas, asares ni arenillas en poca ni en mucha cantidad; por pasatiempo, entretenimiento ni otros casos que subcedan de conversación, dineros, preseas, almuerzos, colaciones ni otra cosa alguna, so pena que la tal persona en cuya casa se jugaren los dichos juegos o cualquiera dellos en la forma susodicha por las dichas mujeres, sea habido y tenido por tablajero público (Cuevas, «Ordenanzas», 330).

En un acta del cabildo de 1588, se registran agresiones derivadas de este tipo de juegos: «Francisco de Solís, alcalde ordinario, informó que habiendo sido comisionado para remediar el exceso en los juegos de naipes y bolos que se tenían en una casa de la calle de San Francisco, fue agredido por Pedro de Villegas, alguacil mayor del Santo Oficio y sobrino del dueño de la casa en cuestión» (AHCM, Acta 4923, 24 de febrero de 1588).

En tiempos de Felipe II, el juego de naipes llegó a ser una fuente de ingresos para el erario público cuando se creó el estanco y pasó a ser propiedad de la Real Hacienda, lo cual era una manera de regular los excesos en el juego con oficiales que visitaban los locales y vigilaban a los coimes, además de obtener ganancias para la caja real (Cuello Martinell 13). Pronto las barajas dejaron de importarse de Espańa y empezaron a fabricarse en México, con lo cual desde 1578-84, precisamente los años en los que se data este coloquio, había casas destinadas a la fabricación de naipes, a cargo de dos oficiales que consignaban en un libro la fabricación de los mismos y «un arca con dos llaves que guardaría el sello». El Ramo se ofrecía al mejor postor y durante el siglo Xvi se estuvo arrendando a particulares, pero, a partir de las Ordenanzas de 1673, empezó a administrarse por cuenta de la Corona con un administrador que cobraba mil pesos (Cuello Martinell 44). Para el Ramo de Naipes se necesitaron reglamentaciones continuas por el contrabando de falsos naipes, importados del extranjero, sobre todo, en el siglo XVII, debido al precio elevado de los que se hacían en la Real Fábrica de Naipes o por la falta de papel; por las fuertes apuestas, que, como se dijo, no podían ser de más de diez pesos de oro al día, cantidad que nunca se respetaba, así como por la ausencia de los jugadores en sus lugares de trabajo o en misa los días festivos, a tal punto que el marqués de Casafuerte decretó en 1725 la prohibición de jugar en días laborales (Cuello Martinell 36-38).

La didascalia nos informa que los dos tahúres, antes de acuchillarse, son separados por un Doctor que iba a recibir al Virrey de parte de las Escuelas, con lo cual el cuadro de los fulleros queda integrado en el ambiente festivo de la ciudad el día del recibimiento; el Doctor les explica la vida de Cristo a través del juego de cartas y se explaya en instruirlos 
sobre la Universidad, sus cátedras y sus doctores más importantes.

Se trata de un coloquio que se emparenta con las Relaciones de fiestas en las que se da cuenta de las recepciones a virreyes, y cuyo protocolo conoce muy bien el dramaturgo porque en el mismo coloquio se escenifica el recibimiento en la ciudad adornada con «luminarias / por terrados y ventanas» (vv. 776-777), y en sus calles «corten ramos y echen flores» (v. 853).

Coloquio VII - De quando Dios Nuestro Señor mandó al profeta Ionás que fuesse a la Ciudad de Níniue a predicar su destruyción (1568-1580). Comienza con un entremés de Diego Moreno y Teresa que trata sobre la prohibición de la seda. Teresa se llama «hija de conquistador", como solían jactarse los criollos presuntuosos de linaje en la disputa de chapetones y baquianos por reivindicar la tierra que sus padres ganaron y regaron con su sangre, pretensión de la que se burla González de Eslava en dos ocasiones más: en el coloquio X, el personaje Ocio también dice: «No tanta burla, señor / que ya proué que soy fino / hijo de conquistador» (X, vv.223-225) y en el XVI, Ocasión habla: «miren quien, por mi dolor, / vino a tener por mujer / nieta de un conquistador» (XVI, vv.1150-1152). La también presuntuosa y linajuda Teresa desea embarcarse para la China porque allí no llegaría "tan aína» la "premática» que había prohibido la seda:

¿Que en México é de quedar?

No haré, assí Dios me ayude.

No lo podré soportar

que vn alguacil me desnude

sin quererme respetar.

No sé qué muger honrada

en este México queda.

Premática pregonada,

y que yo no trayga seda.

Llamaréme malograda. (VII, vv. 1-10)

Nuestros tres editores se preguntan a qué ley suntuaria se refiere Teresa en la primera nota de este coloquio. Dado que fue fechado por el propio Arróniz entre 1568 y 1580 debe aludir, sin duda, a la pragmática del ańo anterior, 1567, en la que se prohibía comerciar estos géneros con Francia, así como usar vestidos con brocados, sedas, telas de oro y plata, ni botones, ni galones, ni pasamanos, ni cordones, ni pespuntes, ni cintas de oro; la prohibición atañía también a los comediantes y músicos, pero estaban exentos los atuendos de los que se dedicaban al culto divino y los uniformes de la caballería, así como cuando se hicieran fiestas a caballo en las plazas públicas. Se permitían, en cambio, tanto para hombres como para mujeres, el terciopelo liso o labrado, negro o de colores; damascos, rasos, tafetanes, etc. La seda sólo se podía usar si era fabricada en el reino o en las provincias amigas con las que se comerciaba. Sin embargo, este uso continuó, porque en 1724, el marqués de Casafuerte tuvo que repetir la prohibición de la venta de seda china, así como los vestidos hechos con la misma tela (Solano 1994, 30).

Este problema del uso suntuario de sedas y terciopelos no pasó desapercibido a González de Eslava, quien dedicó la loa de su coloquio séptimo al virrey Martín Enríquez, y este entremés en el que aparece una figura propia del género entremesil: «la mujer, heredera de la malmaridada de la lírica tradicional. Siempre descontenta con la suerte que le ha correspondido en matrimonio" (Huerta Calvo 128). Teresa, aunque no está del lado de los burladores ni le es infiel al marido, como es usual en los entremeses, lo incordia demasiado y discute continuamente con él porque no le compra ropas de terciopelo que arrastran «cien mil mujeres».

González de Eslava parece ser un gran conocedor de los géneros o telas, de los colores de los paños y de las libreas, como demuestra en el coloquio I, dedicado a los obrajes, y donde parecen latir también los ecos de esta pragmática, ya que se habla de los paños de la tierra como más valiosos que los fabricados en el extranjero:

Viendo este paño luzido, que en sí tanto bien encierra,

Dios, que es Rey en paz y en guerra,

luego quiso ser vestido

deste paño de la tierra. (I, vv. 56-60)

Más adelante, habla la Iglesia:

Quando está bien ocupado

Dale Dios una librea

de su muy fino brocado.

Mas tiene de ser primero

con el baptismo sellado,

porque, si es paño extranjero,

tiene de ser desechado

deste Reyno verdadero. (I, vv. 638-645)

Cabe resaltar que este es el único coloquio en el que los personajes del entremés y de la obra se relacionan a través de la nave que está surta en el puerto y 
en la que se embarcan tanto Diego y Teresa como Ionás, el personaje principal; después de padecer mareos y sufrir una tormenta, Teresa promete, si sale viva de ese trance, «de amar a Diego Moreno / y guardarle lealtad» (VII, vv. 769-770). Se amainan, entonces, en un final feliz, los vientos del mar y los del matrimonio.

Coloquio X - De la esgrima espiritual (1583). En este coloquio hay, sobre todo, referencias a la laguna de la Ciudad:

\author{
Temor ¿Quién causa aquestos hedores? \\ Ignorancia Señor, aquesta laguna, \\ que mucho nos importuna; \\ prouéanlo essos señores, \\ háganse todos a vna. (X, vv. 801-805)
}

Emblema de la Ciudad de México, inspiración para sus poetas con toda la mitología neptúnica, la laguna y sus problemas de inundaciones y hedores dio para rellenar muchos memoriales y eran varias las opiniones de que se agostara, aunque, a juicio de Torquemada, esta solución sería nefasta por las enfermedades que supondrían los polvos salitrales que difundirían el viento y el olor a marisco insoportable, que provocaría tales pestilencias, que mataría a sus habitantes. Lo que propone en este coloquio González de Eslava: "provéanlo essos señores» no se resolvió ni siquiera en el siglo XviII, cuando Cayetano de Cabrera y Quintero culpaba de la epidemia de matlazáhuatl a los suelos húmedos de México, a las lagunas que provocaban «malignas pestilentes fiebres» (Cabrera 32). Pero no solo se denuncian los olores pestilentes, se nombra a sus habitantes «laguneros» $\mathrm{y}$ «atoleros» $\mathrm{y}$ se les califica de ociosos:

Porque en aquesta laguna

la Ociosidad está puesta

sobre el cuerno de la Luna. (X, vv. 33-35).

Coloquio XV - En el recebimiento del excelentíssimo señor Don Luys de Velasco, quando vino por virrey desta Nueua España la primera vez (1590). Otro coloquio dedicado al recibimiento a un virrey, en este caso, Don Luis de Velasco, el joven, que ocupó dos veces el puesto, pero ésta fue la primera y para su llegada se había acordado una serie de festejos, según consta en AHCM, acta 5087, 2 de enero de 1590:

A) Una escaramuza en el Valle de Guadalupe.

B) Que se pase revista a las tropas de infantería.
C) Que se haga un palio de seda.

D) Que se den hachas a cada uno de los regidores.

E) Que se haga bosque en la plaza de México con conejos y venados.

F) Que se organicen juegos de cañas y corridas de toros.

G) Que se haga un arco triunfal en la plaza de Santo Domingo.

$\mathrm{H}) \mathrm{Se}$ organizaron las cuadrillas para el juego de cañas.

Con la experiencia de los años, el despliegue ceremonial en tales festejos se volvió cada vez más complicado, y se le ofrecían en el camino incluso piezas dramáticas para entretener el cansado viaje, como sucedió en este coloquio decimoquinto, que bien pudo representarse en Nuestra Seńora de Guadalupe, donde hizo un alto el virrey para descansar y observar la escaramuza. Allí es adulado en el auto como una preciosa carga que llega de España, hijo digno de su padre, por boca de Esperança:

\author{
Traemos vn Cauallero \\ que será a la Nueua España \\ más que padre verdadero. (XV, vv. 178-180) \\ Sí, la flor de Caualleros, \\ sol deste siglo presente \\ y sol de los venideros. (XV, vv. 278-280) \\ Porque viue este señor \\ en éste su hijo amado, \\ que es su imagen, su traslado, \\ sustancia, ser y valor \\ del padre que lo ha engendrado. (XV, vv. 311-315)
}

Tres ángeles bajan a darle los parabienes y a socorrerlo en el gobierno y, al final del auto, San Miguel lo invita al descanso de las fatigas del viaje:

Escucharnos tan de espacio

es de pecho generoso,

mas, por ser día trabajoso,

Vamos, señor, a palacio

Para que tengáys reposo. (XV, vv. 613-617)

Coloquio XVI - Del bosque diuino donde Dios tiene sus aves y animales (1578). Son numerosas en este coloquio las referencias a la Ciudad: se alude al agua de Santa Fe (XVI, 616), que, como explica Rojas Garcidueñas en su nota, se refería a uno de los acueductos que proveían de agua a la Ciudad (290), pero 
lo cierto es que en esa época era tan solo una fuente; el acueducto de Santa Fe se comenzó a principios del XVII, en tiempos del virrey Juan de Mendoza y Luna, marqués de Montesclaros, y se acabó en 1620 para conducir y repartir el agua en las cuarenta fuentes públicas y en las particulares de jardines y patios; la arquería de Santa Fe llegaba a través de mil y ocho arcos hasta el Puente de la Mariscala.

Más adelante, el personaje Murmuración se acerca en silla y viene quejándose, porque "Como quitaron los coches, ando entregada a la gente de la tierra» (XVI, 624), es decir, a los tamemes o cargadores de personas, sobre todo, cuando había inundaciones en la Ciudad para que no se mojaran. Icazbalceta aduce la pragmática de 1577 sobre la prohibición de los coches, aunque a México llegó el 12 de mayo de 1578 (AHCM, acta 4056). Efectivamente, en 1577, Felipe II dictó una real cédula para que se ejercitara el caballo, porque servía para la «fuerza y defensa de la tierra" y se prohibió absolutamente el uso de coches y carrozas, a todas las personas de cualquier estado, así como importarlos de España o fabricarlos en las Indias. Las multas ascendían a la pérdida de los coches y carrozas, de las mulas y caballos, además de 500 pesos en oro, de los cuales se beneficiaban la cámara y el fisco real, el juez que sentenciaba y la persona que denunciaba; el incumplimiento podía llevar incluso al destierro de las Indias y para que todo el mundo se enterase, se mandaba pregonar desde las gradas de Sevilla hasta las ciudades de México o Lima y otras muchas ciudades americanas (Solano 1996, 240-241). El tema de los caballos no puede aislarse del de los coches, porque en las pragmáticas de la época, uno dependía del otro, se prohibían los coches en beneficio de los caballos por varios motivos, entre ellos, porque se dejaba de ejercitar la caballería y se llegaba al afeminamiento de los caballeros que preferían cambiar las duras ancas y el brío de los corceles por los blandos cojines y el monótono traqueteo de los coches (García Santo-Tomás 94). Pero las prohibiciones y derogaciones alternaban de unas décadas a otras, según la tolerancia del rey en turno, porque, a principios del XviI, en 1625 , cuando Tomas Gage visitaba la ciudad, abundaban a tal extremo los coches que «se creía por muy cierto que había en ese tiempo en la ciudad más de quince mil coches» (Gage 175).

En este coloquio, se alude a los castigos de la justicia novohispana en las voces del Príncipe, Remoquete, Halagüeña y Murmuración, quien explica cómo acabó el padre de Remoquete en la horca y vino a parar «en moneda de cobre», a lo que responde el Príncipe: «¿Quartos quiere dezir?», aludiendo al chiste macabro de hacer cuartos o pedazos a las personas ajusticiadas; sin embargo, ninguno de los editores sabe explicarlo y Arróniz sólo habla del valor de la moneda, pero no del juego que trata de hacer González de Eslava. Lo que extraña es que sí entendieran el doble sentido de cruzados por la moneda y por los azotes que cruzaban las espaldas y no el de cuartos.

Los lugares más importantes de peregrinación: Guadalupe y la Virgen de los Remedios aparecen en los consejos de Templanza a Ocasión, que trata de recuperar el amor de su marido a través de las hechicerías y las hierbas que le dieron las indias.

En este coloquio aparece también la tan citada frase «Poco ganarás a Poeta, que ay más que estiércol» (XVI, 680), que le dice Murmuración a Remoquete, y claro que había estiércol en la capital de la Nueva Espańa, a juzgar por la gran cantidad de caballos.

No puedo dejar de mencionar el coloquio IV (1574-1580) en el que apenas aparecen algunos nombres: Chapultepec, Cuyohuacán, Huaxaca, Cuernauaca y Michuacán y donde se alude a los gremios de cancerberos, o sea, los cerrajeros y herreros, que estaban asentados en la calle de Tacuba. El coloquio XII (1572), en el que se dice que «En la Ciudad mexicana / mira cómo hacen fiesta» (XII, vv. 436-437). El coloquio XIII (1585-1590), en el que aparece un campesino llamado Simple, que se sustenta de los juiles que pesca en la laguna como el mestizo pobre, Juan de Diego, del poema de Rosas de Oquendo, "Ay, señora Juana», que pescaba en la laguna ajolotes y juiles y comía chilmole, aguacates y camotes, pero se jactaba de hidalguía y de ser nieto de conquistadores. El XIV (1576), en el que González de Eslava recogió la epidemia de cocolixtle de 1576, ampliamente comentada por los editores, y a la que yo añadiría que se manifestaba con hemorragias por la nariz y "corazón hinchado», y para cuyo remedio se acudía a las rogativas y a la piedad cristiana, se invocaba a la virgen de los Remedios y se creía en las procesiones de sangre por encima de cualquier otra manifestación religiosa.

Estas anotaciones, tanto de realia (que se refieren a contenidos y alusiones culturales o referencias históricas en el texto, para lo cual busqué documentos de la época, tales como las actas de cabildo, libros de viajeros y cronistas) como las de similia (o las anotaciones de pasajes paralelos o expresiones análogas en textos coetáneos, del mismo género discursivo o incluso del mismo autor), lejos de demostrar erudición impertinente, creo que son necesarias para 
fundamentar ciertas lecturas incomprensibles, como el caso de la brida, y, sobre todo, han pretendido iluminar la época en que vivió González de Eslava y los problemas que acuciaban a su ciudad. Sin embargo, llama poderosamente la atención que no haya dedicado algún coloquio, loa o entremés a alguna inundación como la que le tocó vivir, la de 1580, con el virrey Martín Enríquez, quien mandó que se desaguara la laguna por el canal de Huehuetoca para conducir las aguas al río de Tula, pero no se comenzó la obra (Gemelli 81). No obstante, en su teatro, nos dejó constancia de los graves problemas que afrontaba la Nueva España: los asaltos de los chichimecas; la mortandad de las epidemias; las pragmáticas sobre el lujo tanto de la seda como de los coches; la imposición de las alcabalas que asfixiaba «el comercio de la tierra», como se decía en los documentos oficiales; los juegos de naipes y su reglamentación; el estanco de los obrajes y su prosperidad; la Ciudad enfiestada por el recibimiento de las autoridades civiles o eclesiásticas, etc. y si bien su teatro no tiene un gran valor dramático, es un valioso documento que aporta su cuota a la historia de las mentalidades de la etapa virreinal, así como a la datación de los coloquios, además de la propia participación del dramaturgo en los festejos de recibimiento con su obra dramática.

\section{Bibliografía}

AHCM. Archivo Histórico de la Ciudad de México. Actas de Cabildo, siglo Xvi.

Balbuena, Bernardo de. Grandeza mexicana. Ed. Francisco Monterde. México: UNAM, 1941.

Cabrera y Quintero, Cayetano de. Escudo de Armas de la ciudad de México. Celestial protección de esta nobilissima ciudad de la Nueva España y de casi todo el Nuevo Mundo. México: Viuda de José Bernardo de Hogal, 1746. Ed. moderna de Víctor M. Ruiz Nautal. México: IMSS, 1981. [Accesible en línea: http:// www.cervantesvirtual.com/obra/escudo-de-armas-demexico-sic-celestial-proteccion-de-esta-nobilissimaciudad-de-la-nuevaespana-si-0/].

Cervantes, Miguel de. El ingenioso hidalgo Don Quijote de la Mancha. Ed. Martín de Riquer. Barcelona: Planeta, 1980.

Chevalier, François. «Noticia inédita sobre los caballos en Nueva España». Revista de Indias, 16 (1944): 323-326.

Covarrubias, Sebastián de. Tesoro de la lengua castellana, o española. Madrid, por Luis Sánchez, 1611. [Accesible en línea: http://www. cervantesvirtual.com/obra-visor/del-origen-yprincipio-de-la-lengua-castellana-o-romanceque-oy-se-vsa-en-espana-compuesto-por-el--0/ $\mathrm{html} /]$.

Cuello Martinell, María de los Ángeles. La renta de los naipes en Nueva España (1770-1821). Sevilla: Escuela de Estudios Hispanoamericanos de Sevilla, 1958.

Cuevas, Mariano. «Ordenanzas de don Antonio de Mendoza acerca del juego». México, 29 de julio de 1539. Documentos inéditos del siglo XVI para la Historia de México. 2a ed. México: Porrúa, 1975: 90-92.

Cuevas, Mariano. "Ordenanzas y pregón de la ciudad de México sobre el juego de naipes». México, 19 de julio de 1583. Documentos inéditos del siglo XVI para la Historia de México. 2a ed. México: Porrúa, 1975: 329-330.

Cuevas, Mariano. «Puntos consultados a los PP. Antonio Rubio y Pedro de Hortigosa, S.J., acerca de los obrajes y su parecer acerca de ellos». Documentos inéditos del siglo XVI para la Historia de México. 2a ed. México: Porrúa, 1975: 482-484.

Díaz del Castillo, Bernal. Historia verdadera de la conquista de la Nueva España [1632] (Manuscrito Guatemala). Ed. José Antonio Barbón Rodríguez. México: El Colegio de México-UNAM, 2005.

GAGE, Thomas. Nueva relación que contiene los viajes de Thomas Gage en la Nueva España. París: Librería de Rosa, 1838.

García Santo-Tomás, Enrique. Espacio urbano y creación literaria en el Madrid de Felipe IV. Madrid: Iberoamericana-Vervuert, 2004.

Gemelli Careri, Giovanni Francesco. Viaje a la Nueva España [1698]. México: UNAM, 2002.

González de Eslava, Fernán. Coloquios espirituales y sacramentales. Ed. Joaquín García Icazbalceta. México: Imprenta de F. Díaz de León, 1877.

González de Eslava, Fernán. Coloquios espirituales y sacramentales. 2 vols. Ed. José Rojas Garcidueñas. México: Porrúa, 1976, 2a ed.

González de Eslava, Fernán. Coloquios espirituales y sacramentales. Ed. Othón Arróniz, con la colaboración de Sergio López Mena. México: UNAM, 1998.

González de Eslava, Fernán. Villancicos, romances, ensaladas y otras canciones devotas. Ed. Margit Frenk. México: El Colegio de México, 1989.

Huerta Calvo, Javier. «Entremés». Diccionario de la comedia del Siglo de Oro. Frank P. Casa, Luciano García Lorenzo y Germán Vega García-Luengos (eds.). Madrid: Castalia, 2002: 125-128.

María y Campos, Armando de. Guía de representaciones teatrales en la Nueva España (siglos XVI al XVIII). México: Costa-Amic, 1959. 
Serrera, Ramón María. Tráfico terrestre y red vial en las Indias españolas. 2a ed. Madrid: Ministerio del Interior, Dirección General de Tráfico-Lunwerg Editores, 1993.

Solano, Francisco de. Las voces de la ciudad. México a través de sus impresos (1539-1821). Madrid: CSIC, 1994.

Solano, Francisco de. «Real cédula prohibiendo el uso de coches y carrozas en las ciudades, porque presupone abandono de los ejercicios ecuestres, tan vitales para la defensa de los territorios». Madrid, 24 de noviembre de 1577. Normas y leyes de la ciudad hispanoamericana, 1492-1600. Madrid: CSIC-Centro de Estudios Históricos, 1996, 2 vols.

Zorita, Alonso de. Relación de la Nueva España [1685]. México: CONACULTA, 1999, 2 vols. 
